\title{
Ride comfort evaluation for a double-drum vibratory roller with semi-active hydraulic cab mount system
}

\author{
Nguyen Tien Duy ${ }^{1}$, Le Van Quynh ${ }^{2 *}$, Dang Viet $\mathrm{Ha}^{3}$, Bui Van Cuong ${ }^{2}$ and Le Xuan Long ${ }^{2}$ \\ ${ }^{1}$ Faculty of Electronics Engineering, Thai Nguyen University of Technology, Thai Nguyen 24000, \\ Vietnam \\ ${ }^{2}$ Faculty of Automotive and Power Machinery Engineering, Thai Nguyen University of Technology, \\ Thai Nguyen 24000, Vietnam \\ ${ }^{3}$ Vietnam Register, Ha Noi 12059, Viet Nam
}

\begin{abstract}
The construction machinery market has required increasingly not only on working capacity but also ride comfort quality, therefore it has required increasing toward researchers and manufacturers. The main objective of this paper proposes and evaluates the performance of semi-active hydraulic cab mount system (SHCMs) of a double-drum vibratory roller in the direction of enhancing vehicle ride comfort under different operating conditions. Firstly, a nonlinear dynamic model of passive hydraulic cab mount system (PHCMs) is established to determine its vertical force which is connected with a dynamic model of vehicle - ground surface interaction. And then, a fuzzy logic controller (FLC) is designed to control the value of the damping force of SHCMs. Both the differential equations of motion and FLC are implemented in the MATLAB/Simulink environment. Finally, the ride performance of SHCMs is evaluated under different conditions according to ISO 2631: 1997 (E) standard. The obtained results show that the values of objective functions with SHCMs significantly reduce in comparison with PHCMs under different operating conditions.
\end{abstract}

\section{Introduction}

The earth-moving equipment often operate in harsh environments, sources of vibration are transmitted from the ground deformation, the internal combustion engine as well as the operating mechanism to the cab through cab mount system and driver's seat suspension system. Many research results have shown that driver works for a long time under vibration and shock environment, it can easily cause a series of occupational diseases such as spinal deformities, stomach diseases, etc. Especially, driver exposure for a long time with low frequency and large amplitude vibration which can cause physical discomfort or even diseases [1-2]. The topic of the ride comfort of earth-moving equipment is always of interest to researchers and manufacturers. The auxiliary cab mount system (ACMs) and main cab mount system (MCMs) of a vibratory roller were considered to solve the problem

${ }^{*}$ Corresponding author: lequynh@tnut.edu.vn 
of cab shaking under low frequency excitation and then the design parameters of ACMs were optimized by the finite element method $[3,5]$. An auxiliary damping mount (ADM) of a vibratory roller was proposed to control the cab shaking based on a half-vehicle dynamics model [4]. The design parameters of rubber cab mount system of a single-drum vibratory roller were optimized by GA (Genetic Algorithm) [6] and NSGA II (Non-dominated Sorting Genetic Algorithm II) [7]. The dynamic characteristics of the vibratory roller and mount cab system were analyzed by both simulation and experimental methods [8]. A hydraulic cab mount system (HCMs) of an earth-moving machinery was proposed and evaluated its ride performance in comparison with the rubber cab mount system using a 3D dynamic model of the cab with six degrees of freedom(DOF) [9]. The hydraulic cab mount system (HCMs) of a drum vibratory roller was proposed to evaluate the ride performance in comparison with two types of the rubber cab mount system (RCMs) and pneumatic cab mount system (PCMs) using a 3-D nonlinear vehicle dynamics model with eleven degrees of freedom [10]. The hydro pneumatic cab mount system (HPCMs) of a vibratory roller was proposed investigate the ride effectiveness of HPCMs in the direction of enhancing vehicle ride comfort [11]. In order to enhance the off-road vehicle ride comfort, many control methods have been used to control the semi-active or active mount systems of earth-moving equipment. A combination of fuzzy logic controller and PID controller was applied to control the damping coefficient of semi-active cab mount system of vibratory roller using a nonlinear vehicle dynamic model [12]. A fuzzy logic controller (FLC) was designed to control the damping coefficient value of the semi-active hydropneumatic cab mount system of a vibratory roller [13]. Similarly, a fuzzy controller was designed to control a kind of magneto-rheological (MR) damper of a semi-active mount system of vibratory roller using a 2-DOF dynamic model [14]. An optimal fuzzy-PID control method was designed to control for a semi-active hydraulic cab mount system using a three-dimensional nonlinear dynamic model of vibratory roller[15].

The main idea of this paper is to propose a semi-active hydraulic cab mount system (SHCMs) for a double-drum vibratory roller based on the development of the structure of a passive hydraulic cab mount system (PHCMs) with adjustable hydraulic damping force of hydraulic actuator. Firstly, a nonlinear dynamic model of passive hydraulic cab mount system (PHCMs) is established to determine its vertical force which is connected with a dynamic model of vehicle - ground surface interaction. And then, a fuzzy logic controller (FLC) is designed to control the value of the damping force of SHCMs. Finally, the ride performance of SHCMs is evaluated through the root-mean-square (RMS) of acceleration responses $\left(\mathrm{a}_{\mathrm{ws}}, \mathrm{m} / \mathrm{s}^{2}\right.$ and $\left.\mathrm{a}_{\mathrm{wcphi}}, \mathrm{rad} / \mathrm{s}^{2}\right)$ based on ISO 2631: 1997 (E) standard [16] when vehicle operates under survey conditions.

\section{Nonlinear dynamic model of hydraulic cab mount}

\subsection{Passive hydraulic cab mount (PHCM)}

The structural diagram of a passive hydraulic cab mount (PHCM) with the orifices consists of rubber part, two oil chambers such as lower and upper chambers, and the fluid flowing up and down through the orifice derived from the damping plate driven by the bolt, the damping plate and the orifices, as shown in Fig.1(a). A nonlinear dynamics model is established based on the structural diagram of Fig.1(a) to determine its vertical force, as shown in Fig. 1 (b), where, $m_{c}$ and $m_{b}$ are vehicle body mass and cab mass, respectively, $p_{1}$ and $\mathrm{p}_{2}$ are the upper liquid chamber and the lower liquid chamber, respectively, $\mathrm{z}_{\mathrm{c}}$ and $\mathrm{z}_{\mathrm{b}}$ are the vertical displacements of cab and vehicle body masses, respectively, $k_{r}$ and $c_{r}$ are 
stiffness and damping coefficients of rubber part, respectively and $F_{c}$ is the total vertical forces of hydraulic cab mount.

Based on Fig. 1 (b), the total vertical forces of PHCM could be achieved by

$$
F_{c h}=F_{r}+F_{h}
$$

where, $F_{r}$ is the vertical force of rubber part which is defined by Eq.(2) and $F_{h}$ is the damping force of the hydraulic actuator with the orifices which is defined by Eq.(7).

$$
F_{r}=k_{r}\left(z_{c}-z_{b}\right)+c_{r}\left(\dot{z}_{c}-\dot{z}_{b}\right)
$$

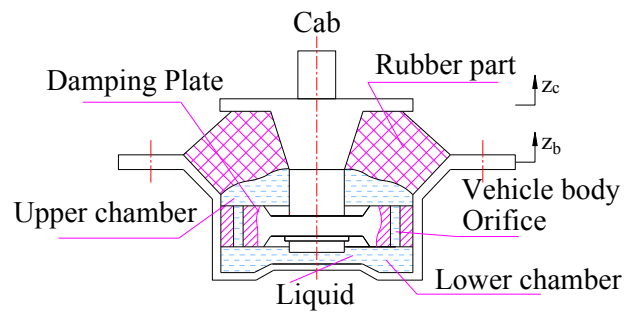

(a) Structural diagram of PHCM

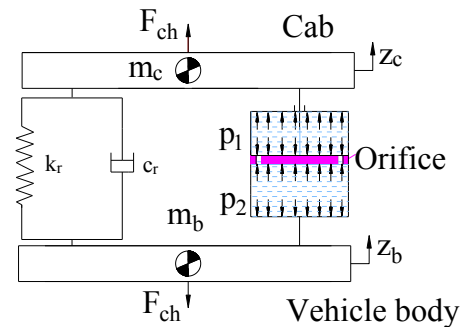

(b) Nonlinear dynamical model of PHCM

Fig. 1. Model of a passive hydraulic cab mount (PHCM) with the orifices.

The damping force of PHCM is determined by

$$
F_{h}=\Delta p A_{d}
$$

where, $\Delta \mathrm{p}$ is the pressure loss at the orifices, $\mathrm{A}_{\mathrm{d}}$ is the effective area of the damping plate.

Based on the reference $[10,17]$, the pressure loss at the orifices is determined by

$$
\Delta p_{0}=c_{0}\left|\dot{z}_{0}\right| \dot{z}_{0}
$$

where, $\mathrm{c}_{0}$ is the positive constant which is function of the geometry of the orifice and the fluid property, and $\dot{z}_{0}$ is the average flow velocities in the orifices

The equation of continuity for the flow through the orifice is written as follows

$$
A_{c} \dot{z}=A_{a} \dot{z}_{a}
$$

where, $\mathrm{A}_{\mathrm{c}}$ and $\mathrm{A}_{\mathrm{a}}$ are the effective area of the chamber and the orifices, respectively, $\dot{z}$ is the relative velocity between the displacements of the vehicle body and cab masses.

Substitute Eq. (5) into Eq. (4), the pressure loss at the orifices can be achieved by

$$
\Delta p_{0}=c_{0}\left(\frac{A_{c}}{A_{a}}\right)^{2}|\dot{z}| \dot{z}
$$

Substitute Eq. (6) into Eq. (4), the vertical damping force of the hydraulic actuator with the fluid flow through the orifices can be achieved by

$$
F_{h}=c_{0} A_{d}\left(\frac{A_{c}}{A_{a}}\right)^{2}|\dot{z}| \dot{z}=c_{f}|\dot{z}| \dot{z}
$$

\subsection{Semi-active hydraulic cab mount (SHCM)}

A control model for a semi-active hydraulic cab mount (SHCM) is developed from a model of passive hydraulic cab mount (PHCM) in Fig.1(b) with adjustable hydraulic damping force of hydraulic actuator, as shown in Fig.2, where, $\mathrm{c}_{\mathrm{semi}}$ is the variable damping coefficient of hydraulic actuator of SHCM.

Based on Fig. 2, the total vertical forces of PHCM could be achieved by

$$
F_{c s}=F_{r}+F_{h}+f
$$




\section{ICECAE 2021}

where, $F_{r}$ is the vertical force of rubber part which is defined by Eq.(2), $F_{h}$ is the damping force of the hydraulic actuator with the orifices which is defined by Eq.(7) and $f$ is the adjustable damping force of the hydraulic actuator which is defined by fuzzy logic controller.

The controller design for a semi-active hydraulic cab mount (SHCM) of a double-drum vibratory roller will be presented below

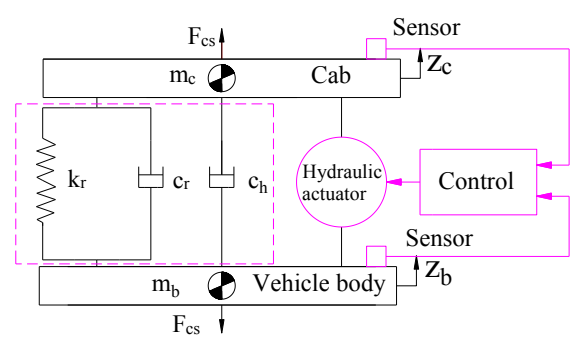

(a) Schematic of SHCM

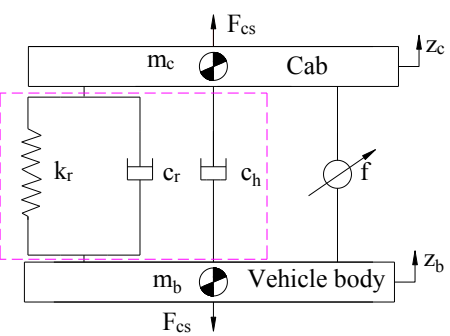

(b) Dynamical model of SHCM

Fig. 2. Model of a semi-active hydraulic cab mount (SHCM).

Design of fuzzy logic controller (FLC): To adjust damping force of hydraulic actuator of the SHCM, a fuzzy logic controller is is designed with two input variables such the relative displacement of SHCM, e and the relative velocity of SHCM $c_{e}$ and an output control variable damping force of SHCM $\mathrm{f}$. Seven triangular fuzzy sets for input/output variables including NB, NM, NS, ZE, PS, PM, PB in Table 1. The domain of variables are defined by e $\in[-0.4,0.4] \mathrm{m}, \quad$ e $\in[-0.8,0.8] \mathrm{m} / \mathrm{s}$ and $\mathrm{f} \in[-2000,2000] \mathrm{N}$. The values of the shape of membership functions are between 0 and 1 . The control law system is designed as shown in Table 2.

Table 1. Language label symbols for fuzzy sets

\begin{tabular}{|c|c|c|c|c|c|c|}
\hline NB & NM & NS & ZE & PS & PM & PB \\
\hline $\begin{array}{c}\text { Negative } \\
\text { Big }\end{array}$ & $\begin{array}{c}\text { Negative } \\
\text { Medium }\end{array}$ & $\begin{array}{c}\text { Negative } \\
\text { Small }\end{array}$ & Zero & $\begin{array}{c}\text { Positive } \\
\text { Small }\end{array}$ & $\begin{array}{c}\text { Positive } \\
\text { Medium }\end{array}$ & $\begin{array}{c}\text { Positive } \\
\text { Big }\end{array}$ \\
\hline
\end{tabular}

Table 2. Rule base for fuzzy control

\begin{tabular}{|c|c|c|c|c|c|c|c|c|}
\hline \multicolumn{2}{|c|}{} & \multicolumn{9}{c|}{ e } \\
\cline { 3 - 9 } \multicolumn{2}{|c|}{} & NB & NM & NS & ZE & PS & PM & PB \\
\hline \multirow{4}{*}{ ec } & NB & PB & PB & PB & PB & PS & PS & ZE \\
\cline { 2 - 9 } & NM & PB & PM & PM & PM & PM & ZE & NS \\
\cline { 2 - 9 } & NS & PB & PM & PM & PS & ZE & NS & NM \\
\cline { 2 - 9 } & ZE & PB & PM & PS & ZE & NS & NM & NM \\
\cline { 2 - 9 } & PS & PM & PS & ZE & NS & NM & NM & NB \\
\cline { 2 - 9 } & PM & PS & ZE & NB & NM & NB & NB & NB \\
\cline { 2 - 9 } & PS & ZE & NB & NM & NB & NB & NB & NB \\
\hline
\end{tabular}

\section{Half-vehicle Dynamic Model}

A structure diagram of a double-drum vibratory roller is selected for the ride performance evaluation of a semi-active hydraulic cab mount system (SHCMs) which consists of the mount and suspension systems such as the dynamic drum mount systems, the cab mount system and driver's seat suspension system, as shown in Fig.3. A dynamic model of vehicle - ground surface interaction is developed from the structure of a double-drum vibratory roller in Fig.3, as shown in Fig.4 where, $m_{d i}, m_{b}, m_{c}$ and $m_{s}$ are the masses of the dynamic drums, frame, cab and driver's seat, respectively; $I_{b}$ and $I_{c}$ are the moment of inertia of $\mathrm{m}_{\mathrm{b}}$ 
and $\mathrm{m}_{\mathrm{c}}$, respectively; $k_{s i}, k_{d i}, k_{s}$ and $c_{s i}, c_{d i}, c_{s}$ are the stiffness and damping coefficients of elastic road surfaces, front and rear mount systems of drums and driver's seat suspension system, respectively; $z_{d i}, z_{b}, z_{c}$ and $z_{s}$ are the vertical displacements of the front and rear drums, vehicle body, cab and driver's seat, respectively; $\varphi_{b}$ and $\varphi_{c}$ are the pitch angle displacements of vehicle body and cab, respectively; $\mathrm{q}_{\mathrm{i}}$ are the front and rear drum absolute hard road excitations, respectively; $l_{j}$ are the distances; $F_{e i}=F_{0 i} \sin \left(\omega_{i} t\right)$ are the force excitations of the dynamic drums; $\mathrm{F}_{0 \mathrm{i}}$ are the amplitude of force excitations; $\omega_{i}$ are the angular frequencies of the vibrators; $\mathrm{F}_{\mathrm{ci}}$ are the vertical forces of cab mount system and $v$ is the vehicle speed $(i=1 \div 2, j=1 \div 6)$.

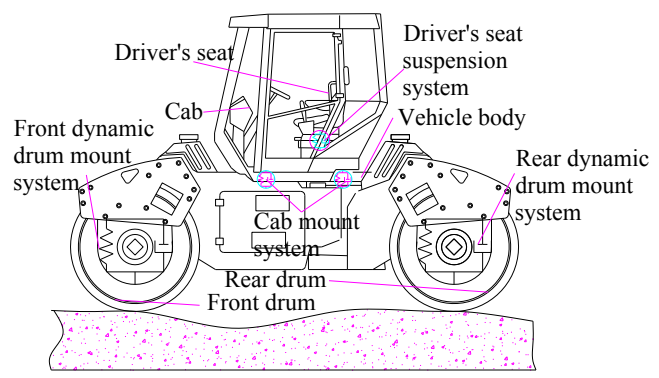

Fig. 3. Structure diagram of a double-drum vibratory roller

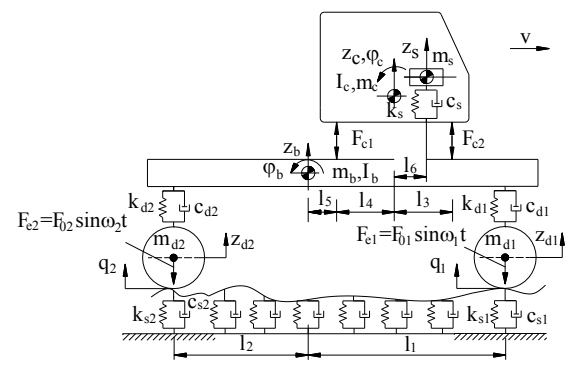

Fig. 4. A dynamic model of vehicle ground surface interaction

The differential equation describing the vibrations in Fig.4. are written by a combined method of the multi-body system theory and D'Alembert's principle.

The vibration equation of the vertical driver's seat is written as follows

$$
m_{s} \ddot{z}_{s}=k_{s}\left(z_{s}-z_{c}-l_{6} \varphi_{c}\right)+c_{s}\left(\dot{z}_{s}-\dot{z}_{c}-l_{6} \dot{\varphi}_{c}\right)
$$

The vibration equations of the vertical and pitching cab are written as follows

$$
\begin{array}{r}
m_{c} \ddot{z}_{c}=\left[k_{s}\left(z_{s}-z_{c}-l_{6} \varphi_{c}\right)+c_{s}\left(\dot{z}_{s}-\dot{z}_{c}-l_{6} \dot{\varphi}_{c}\right)\right]-\sum_{i=1}^{i=2} F_{c i} \\
I_{c} \varphi_{c}=\left[k_{s}\left(z_{s}-z_{c}-l_{6} \varphi_{c}\right)+c_{s}\left(\dot{z}_{s}-\dot{z}_{c}-l_{6} \dot{\varphi}_{c}\right)\right] l_{6}+\sum_{i=1}^{i=2}(-1)^{i} F_{c i} l_{i+2}
\end{array}
$$

where, $F_{c i}$ is the total vertical forces of cab mount system which is is defined by Eq.(12).

$$
F_{c i}=F_{r i}+F_{h i}+\left\{\begin{array}{lll}
0 & \text { with } & \text { PHCMs } \\
f_{i} & \text { with } & \text { SHCMs }
\end{array}\right.
$$

The vibration equations of the vertical and pitching vehicle body are written as follows

$$
\begin{gathered}
m_{b} \ddot{z}_{b}=\sum_{i=1}^{i=2} F_{c i}-\sum_{i=1}^{i=2} F_{d i} \\
I_{b} \varphi_{b}=\sum_{i=1}^{i=2}(-1)^{i} F_{d i} l_{i}+F_{c 2} l_{5}+F_{c 1} \sum_{j=3}^{j=5} l_{j}
\end{gathered}
$$

where, $F_{\mathrm{di}}$ are the vertical forces of front and rear mount systems of dynamic drums which could be determined through two cases.

Case 1: Vehicle operates in the workshop

Condition1: When both front and rear drums compact on the original place, the differential equations describing the vertical vibrations of dynamic drums are written as follows

$$
\begin{aligned}
& m_{d 1} \ddot{z}_{d 1}=F_{e 1}+F_{d 1}-k_{s 1} z_{d 1}-c_{s 1} \dot{z}_{d 1} \\
& m_{d 2} \ddot{z}_{d 2}=F_{e 2}+F_{d 2}-k_{s 2} z_{d 2}-c_{s 2} \dot{z}_{d 2}
\end{aligned}
$$

Condition 2: When front or rear dynamic drum compact on the elastic soil grounds, and rear or front dynamic drum moves on the rigid ground surfaces, the differential equations 
describing the vertical vibrations of front or rear dynamic drums is determined by Eq. (15) or Eq.(16) and the vertical force of rear or front dynamic drum mount system is determined by Eq.(18) or Eq.(17).

Case 2: Vehicle moves into the workshop

Vehicle moves on a variety of ground surfaces such as the absolute hard and deformed ground surfaces. The dynamic drums move on the absolute hard road surface. The vertical forces of front and rear mount systems of dynamic drums are defined as

$$
\begin{aligned}
& F_{d 1}=k_{d 1}\left(z_{b}+l_{1} \varphi_{b}-q_{1}\right)+c_{d}\left(\dot{z}_{b}+l_{1} \dot{\varphi}_{b}-\dot{q}_{1}\right) \\
& F_{d 2}=k_{d 2}\left(z_{b}-l_{2} \varphi_{b}-q_{2}\right)+c_{d 2}\left(\dot{z}_{b}-l_{2} \dot{\varphi}_{b}-\dot{q}_{2}\right)
\end{aligned}
$$

where, $\mathrm{q}_{1}$ and $\mathrm{q}_{2}$ are the front - rear drum absolute hard road excitations according to the International Standards Organization (ISO 8608) [23].

\section{Results and Discussion}

To solve the equations describing the vibrations in Fig.4 and design the fuzzy logic controller (FLC) for the ride performance evaluation of a semi-active hydraulic cab mount system (SHCMs) compared to the passive hydraulic cab mount system (PHCMs), Matlab /Simulink environment software is applied to simulate and control with a set of parameters of the vehicle, the PHCMs, the elastic soil ground and road surface roughness in the references $[19,20]$. The comparison results of $\mathrm{a}_{\mathrm{s}}$ (Time domain acceleration response of the vertical driver's seat) and $\mathrm{a}_{\mathrm{cphi}}$ (Time domain acceleration response of cab's pitch angle) with SHCMs and PHCMs when the front drum compacts with the soil ground parameters as $\mathrm{k}_{\mathrm{s} 1}=1.0 \times 10^{7} \mathrm{~N} / \mathrm{m}, \mathrm{c}_{\mathrm{s} 1}=2.1 \times 10^{5}(\mathrm{~N} . \mathrm{s} / \mathrm{m})$ and the excitation force as $\mathrm{F}_{01}=0.128 \times 10^{6} \mathrm{~N}$, $\mathrm{f}_{1}=48 \mathrm{~Hz}$ and rear drum moves the very poor ground surface (ISO class E) at $\mathrm{v}=3.5 \mathrm{~km} / \mathrm{h}$ (Condition 2 of Case 1) are shown in Fig. 5.

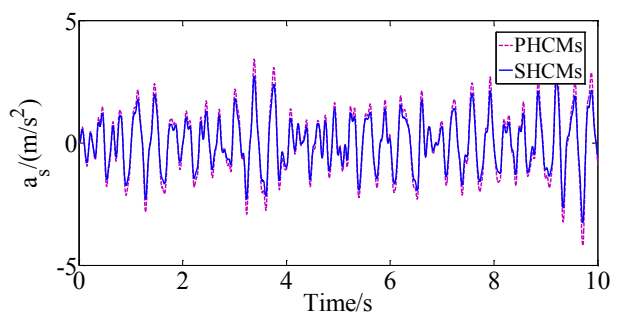

(a) $a_{\mathrm{s}}$

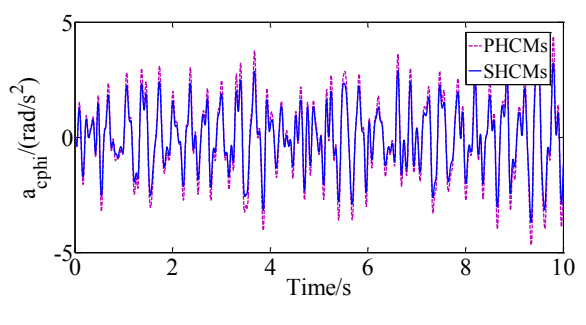

(b) $\mathrm{a}_{\text {cphi }}$

Fig. 5. The comparison results of $a_{s}$ and $a_{\text {cphi }}$ with SHCMs and PHCMs when the front drum compacts and rear drum moves under Condition 2 of Case 1.

The comparison results in Fig.5 show that the peak amplitude values of $a_{s}$ and $a_{\text {cphi }}$ with SHCMs respectively decrease compared to the PHCMs. Furthermore, we could be determined the values of $\mathrm{a}_{\mathrm{ws}}$ and $\mathrm{a}_{\mathrm{wcphi}}$ through Eq. (19) as $\mathrm{a}_{\mathrm{ws}}=1.2865 \mathrm{~m} / \mathrm{s}^{2}, \mathrm{a}_{\mathrm{wcphi}}=1.6970$ $\mathrm{rad} / \mathrm{s}^{2}$ with PHCMs and $\mathrm{a}_{\mathrm{ws}}=1.0305 \mathrm{~m} / \mathrm{s}^{2}, \mathrm{a}_{\mathrm{wcphi}}=1.3393 \mathrm{rad} / \mathrm{s}^{2}$ with SHCMs. The obtained results show that the $\mathrm{a}_{\mathrm{ws}}$ and $\mathrm{a}_{\mathrm{wcphi}}$ values with $\mathrm{SHCMs}$ respectively improve by $24.84 \%$ and 26.71\% compared to PHCMs.

The values of $\mathrm{a}_{\mathrm{ws}}$ and $\mathrm{a}_{\mathrm{wphi}}$ according to ISO standard 2631-1:1997 [16] are chosen as the objective functions which are defined by the formula below

$$
a_{w s}=\left[1 / T \int_{0}^{T} a_{s}^{2}(t) d t\right]^{\frac{1}{2}} \quad \text { and } \quad a_{w c p h i}=\left[1 / T \int_{0}^{T} a_{c p h i}^{2}(t) d t\right]^{\frac{1}{2}}
$$


where, $\mathrm{T}$ is the simulation time in $\mathrm{s}$.

Similarly, the comparison results of $\mathrm{a}_{\mathrm{s}}$ an $\mathrm{a}_{\text {cphi }}$ with SHCMs and PHCMs when vehicle moves on the poor ground surface (the ISO class D) at $\mathrm{v}=5 \mathrm{~km} / \mathrm{h}$ (Case2) are shown in Fig.6.

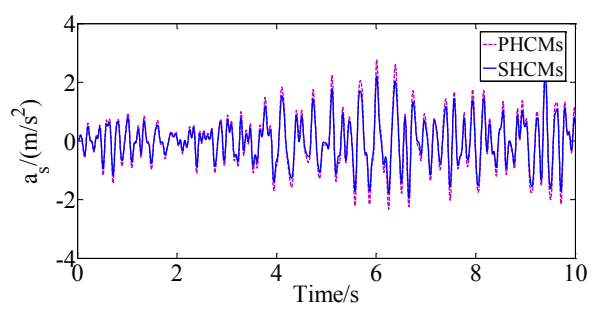

(a) $a_{s}$

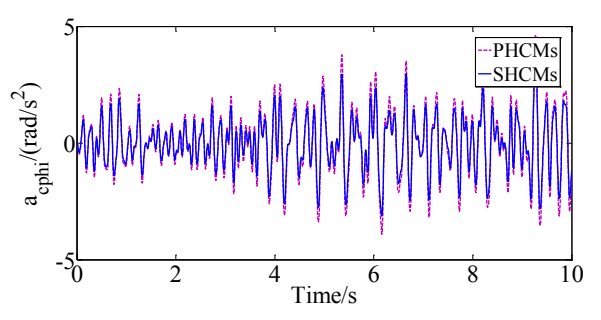

(b) $\mathrm{a}_{\text {cphi }}$

Fig. 6. The comparison results of $a_{s}$ and $a_{\text {cphi }}$ with SHCMs and PHCMs at Case 2

The comparison results in Fig. 6 could be determined the values of the values of $a_{w s}$ and $\mathrm{a}_{\mathrm{wcphi}}$ as $\mathrm{a}_{\mathrm{ws}}=0.8982 \mathrm{~m} / \mathrm{s}^{2}, \mathrm{a}_{\mathrm{wcphi}}=1.3667 \mathrm{rad} / \mathrm{s}^{2}$ with PHCMs and $\mathrm{a}_{\mathrm{ws}}=0.7307 \mathrm{~m} / \mathrm{s}^{2}, \mathrm{a}_{\mathrm{wcphi}}=$ $1.1111 \mathrm{rad} / \mathrm{s}^{2}$ with SHCMs. The obtained results show that the $\mathrm{a}_{\mathrm{ws}}$ and $\mathrm{a}_{\mathrm{wcphi}}$ values with SHCMs respectively improve by $22.92 \%$ and $23.00 \%$ compared to PHCMs at Case 2.

The ride performance of SHCMs in comparison with PHCMs is verified and evaluated under several operating conditions.

Case 1 such as the both front and rear drums compact on the original place (Condition 1 of Case 1 with the soil ground parameters as $\mathrm{k}_{\mathrm{sl}}=1.0 \times 10^{7} \mathrm{~N} / \mathrm{m}, \mathrm{c}_{\mathrm{sl}}=2.1 \times 10^{5} \mathrm{~N} . \mathrm{s} / \mathrm{m}$ and $\mathrm{k}_{\mathrm{s} 2}=1.2 \times 10^{7} \mathrm{~N} / \mathrm{m}, \mathrm{c}_{\mathrm{s} 2}=2.8 \times 10^{5} \mathrm{~N} . \mathrm{s} / \mathrm{m}$ at the front and rear drum excitation forces as $\mathrm{F}_{01}=0.128 \times 10^{6} \mathrm{~N}, \mathrm{f}_{1}=48 \mathrm{~Hz}$ and $\mathrm{F}_{02}=0.96 \times 10^{5} \mathrm{~N}, \mathrm{f}_{2}=54 \mathrm{~Hz}$ ), the front drum compacts and rear drum moves the very poor ground surface (ISO class E) at $\mathrm{v}=3.5 \mathrm{~km} / \mathrm{h}$ (Condition 2 of Case 1), and the rear drum compacts and front drum moves the very poor ground surface at $\mathrm{v}=3.5 \mathrm{~km} / \mathrm{h}$ (Condition 3 of Case 1 with the soil ground parameters as $\mathrm{k}_{\mathrm{s} 2}=1.2 \times 10^{7} \mathrm{~N} / \mathrm{m}$, $\mathrm{c}_{\mathrm{s} 2}=2.8 \times 10^{5} \mathrm{~N} . \mathrm{s} / \mathrm{m}$ at the rear drum excitation force as $\mathrm{F}_{02}=0.96 \times 10^{5} \mathrm{~N}, \mathrm{f}_{2}=54 \mathrm{~Hz}$ ). The values of $\mathrm{a}_{\mathrm{ws}}$ and $\mathrm{a}_{\mathrm{wcphi}}$ at Conditions of Case 1 are shown in Fig.7. The comparison results show that the $a_{w s}$ and $a_{w c p h i}$ values with SHCMs respectively improved by $21.13 \%$ and $22.09 \%$ with Condition $1,24.84 \%$ and $26.71 \%$ with Condition 2 and $24.65 \%$ and $22.10 \%$ with Condition 3 in comparison with PHCMs.

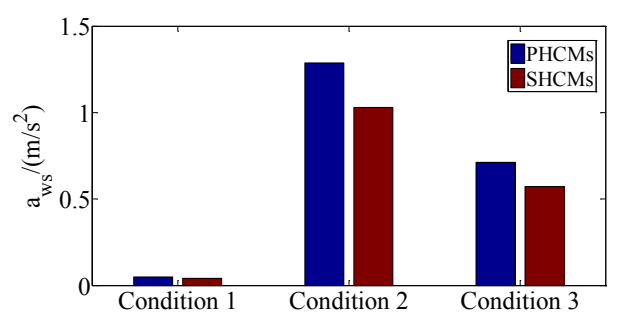

(a) $a_{w s}$

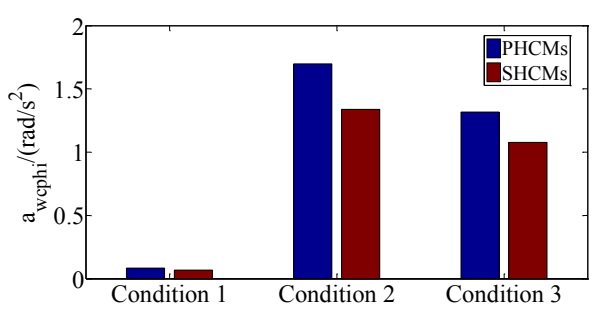

(b) $\mathrm{a}_{\mathrm{wcphi}}$

Fig. 7. The comparison results of $\mathrm{a}_{\mathrm{ws}}$ and $\mathrm{a}_{\mathrm{wcphi}}$ with SHCMs and PHCMs at three different conditions of Case 1

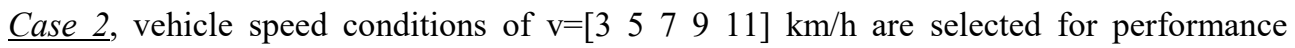
evaluation of SHCMs when vehicle moves on the poor ground surface (ISO class D). The values of the values of $\mathrm{a}_{\mathrm{ws}}$ and $\left(\mathrm{a}_{\mathrm{wcphi}}\right.$ at vehicle speed conditions of Case 2 are shown in Fig.8. The different ground surface conditions from the very good ground surface (ISO 
class A) to very poor ground surface (ISO class E) are selected for performance evaluation at $\mathrm{v}=5 \mathrm{~km} / \mathrm{h}$. The values of $\mathrm{a}_{\mathrm{ws}}$ and $\mathrm{a}_{\mathrm{wcphi}}$ at the ground surface conditions of Case 2 are shown in Fig.9.

The comparison results in Fig. 8 show that the values of $a_{w s}$ and $a_{w c p h i}$ with SHCMs respectively improve by $22.28 \%$ and $22.03 \%$ with $\mathrm{v}=3 \mathrm{~km} / \mathrm{h}, 22.92 \%$ and $23.00 \%$ with $\mathrm{v}=5 \mathrm{~km} / \mathrm{h}, 23.35 \%$ and $22.95 \%$ with $\mathrm{v}=7 \mathrm{~km} / \mathrm{h}, 27.11 \%$ and $26.44 \%$ with $\mathrm{v}=9 \mathrm{~km} / \mathrm{h}$ and $26.29 \%$ and $26.23 \%$ with $\mathrm{v}=11 \mathrm{~km} / \mathrm{h}$ compared to PHCMs.

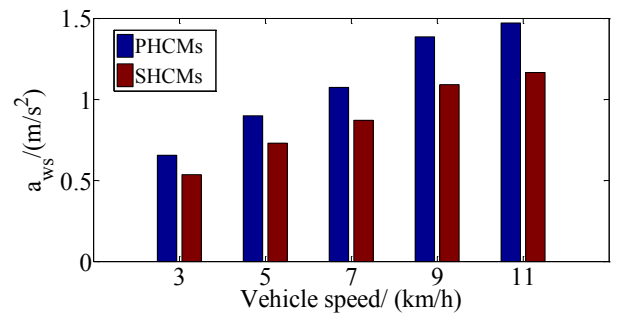

(a) $\mathrm{a}_{\mathrm{ws}}$



(b) $a_{\text {wphi }}$

Fig. 8. The comparison results of the $\mathrm{a}_{\mathrm{ws}}$ and $\mathrm{a}_{\mathrm{wcphi}}$ with SHCMs and PHCMs at five different vehicle speed conditions of Case 2



(a) $a_{w s}$

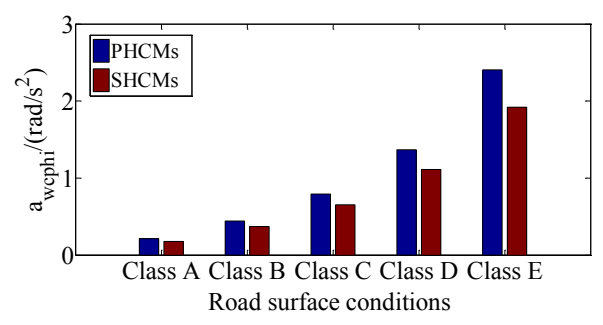

(b) $a_{\text {wphi }}$

Fig. 9. The comparison results of $a_{w s}$ and $a_{w c p h i}$ with SHCMs and PHCMs at five different road surface conditions of Case 2

Similarly, the comparison results in Fig.9 show that the values of $a_{w s}$ and $a_{w c p h i}$ with SHCMs significantly decrease compared to PHCMs when ground surface conditions become bad. The results reflect that vehicle ride comfort with SHCMs is better than the PHCMs results as indicated by $\mathrm{a}_{\mathrm{ws}}$ and $\mathrm{a}_{\mathrm{wcphi}}$ values. Thus, the ride performance of SHCMs with FLC has significantly improved vehicle ride comfort compared to PHCMs under low excitation frequencies and large amplitudes of road surface.

\section{Conclusions}

In this paper, a semi-active hydraulic cab mount system (SHCMs) of a double-drum vibratory roller was proposed on the basis of the development of the structure of a passive hydraulic cab mount system (PHCMs) with adjustable damping force of hydraulic actuator. The FLC was used to control damping force of SHCMs. The ride performance of SHCMs was evaluated based on a dynamic model of vehicle - ground surface interaction under survey conditions and ISO 2631-1(1997). The main study conclusions drawn from the comparative evaluation results are: (1) The values of $a_{w s}$ and $a_{w c p h i}$ with SHCMs respectively improve by $22.92 \%$ and $23.00 \%$ in comparison with PHCMs at Condition 2 of 
Case 1 and the ride performance of SHCMs has significantly reduced vibrations compared to PHCMs at Condition 2 of Case1; (2) the values of $a_{w s}$ and $a_{w c p h i}$ with SHCMs respectively improve by $22.92 \%$ and $23.00 \%$ compared to PHCMs at Case 2 and (3) The ride performance of SHCMs has significantly improved vehicle ride comfort compared to PHCMs under the survey conditions. In addition, the obtained results give a useful material for researchers and manufacturers in the field of suspension system and mount system design for earth-moving machinery.

\section{Acknowledgment}

The work described in this paper was supported by Thai Nguyen University (TNU), Thai Nguyen University of Technology (TNUT) for a scientific project (Code: DH2019 -TN02 01).

\section{References}

1. Griffin M J., Handbook of Human Vibration., London: Academic Press, 1990

2. Hostens I, Ramon H., J. Sound Vib., 266, 2 (2003)

3. Quynh, L. V., Zhang, J. R., Jiao, G. W., Liu, X. B., \& Wang, Y., Advanced Materials Research, 199-200, (2011).

4. Jiao, Renqiang, Vanliem Nguyen, Vanquynh Le, and Peiling Wang, Mathematical Models in Engineering, 6, 1 (2020)

5. Quynh, L. V., Jianrun, Z., Liem, N. V., Cuong, B. V., Long, L. X., \& Phuong, D. T., Vibroengineering PROCEDIA, 31, (2020)

6. Van Quynh L., Duy N.T., Van Liem N., Van Cuong B., Long L.X., Advances in Engineering Research and Application. ICERA 2020. Lecture Notes in Networks and Systems, 178 (2021)

7. Le, V. Q., \& Nguyen, K. T., Applied Mechanics and Materials, 875, (2018)

8. Li, J., Zhang, Z., Xu, H., \& Feng, Z., Journal of Terramechanics, 56, (2014)

9. Nguyen, V., Zhang, J., Le, V., \& Jiao, R., Shock and Vibration, (2018)

10. Sun X., Zhang, J., Journal of Vibration and Control, 20, 5 (2012)

11. Nguyen, V., Jiao, R., \& Le, V., Journal of Vibroengineering, 22, 5, (2020)

12. R. Jiao, V. Nguyen, V. Le, and A. Hoang, Mathematical Models in Engineering, 5, 4, (2019).

13. Nguyen, V., Li, Y., Guo, X., \& Kang, Y., Journal of Mechatronics and Artificial Intelligence in Engineering, 2, 1, (2021)

14. Liu, S. N., Yan, S. R., Li, S. W., \& Zheng, Y. G., Advanced Materials Research, 479481, (2012).

15. Nguyen, V., Zhang, J., \& Yang, X.,. Shock and Vibration, (2019)

16. ISO 2631-1. Mechanical Vibration and Shock-Evaluation of Human Exposure to Whole-Body Vibration, Part I: General Requirements. The International Organization for Standardization, (1997)

17. Jiao, S., Wang, Y., Zhang, L., \& Hua, H., Mechanical Systems and Signal Processing. 24, 5 (2010)

18. L. V. Quynh, J. Zhang, et al., Chinese Soc. Agric. Eng., 29, 9, (2013) 
19. ISO 8608. Mechanical Vibration-Road Surface Profiles-Reporting of Measured Data. International Organization for Standardization, 1995

20. Le Van Quynh, Science research topic: Thai Nguyen University. Thai Nguyen, Vietnam, 2021. 